\title{
Impact of a Dedicated Noninvasive Ventilation Team on Intubation and Mortality Rates in Severe COPD Exacerbations
}

\author{
Stéphanie Vaudan, Damian Ratano MD, Philippe Beuret MD, John Hauptmann, \\ Olivier Contal PhD, and Nicolas Garin MD
}

\begin{abstract}
BACKGROUND: Compared with usual care, noninvasive ventilation (NIV) lowers the risk of intubation and death for subjects with respiratory failure secondary to COPD exacerbations, but whether administration of NIV by a specialized, dedicated team improves its efficiency remains uncertain. Our aim was to test whether a dedicated team of respiratory therapists applying all acute NIV treatments would reduce the risk of intubation or death for subjects with COPD admitted for respiratory failure. METHODS: We carried out a retrospective study comparing subjects with COPD admitted to the ICU before (2001-2003) and after (2010-2012) the creation of a dedicated NIV team in a regional acute care hospital. The primary outcome was the risk of intubation or death. The secondary outcomes were the individual components of the primary outcome and ICU/hospital stay. RESULTS: A total of 126 subjects were included: 53 in the first cohort and 73 in the second. There was no significant difference in the demographic characteristics and severity of respiratory failure. Fifteen subjects $(\mathbf{2 8 . 3 \%})$ died or had to undergo tracheal intubation in the first cohort, and only 10 subjects $(13.7 \%)$ in the second cohort (odds ratio $0.40,95 \%$ CI $0.16-0.99$, $P=.04)$. In-hospital mortality $(15.1 \%$ vs $4.1 \%, P=.03)$ and median stay (ICU: 3.1 vs $1.9 \mathrm{~d}, P=.04$; hospital: 11.5 vs $9.6 \mathrm{~d}, P=.04)$ were significantly lower in the second cohort, and a trend for a lower intubation risk was observed $(20.8 \%$ vs $11 \% P=.13)$. CONCLUSIONS: The delivery of NIV by a dedicated team was associated with a lower risk of death or intubation in subjects with respiratory failure secondary to COPD exacerbations. Therefore, the implementation of a team administering all NIV treatments on a $24-\mathrm{h}$ basis should be considered in institutions admitting subjects with COPD exacerbations. Key words: noninvasive ventilation; chronic obstructive pulmonary disease; COPD; acute respiratory failure; respiratory therapist; ICU; intubation rate; mortality rate; stay. [Respir Care 2015;60(10):1404-1408. () 2015 Daedalus Enterprises]
\end{abstract}

\section{Introduction}

Noninvasive ventilation (NIV) is indicated as a treatment for chronic and acute respiratory failure of different

\footnotetext{
Ms Vaudan and Mr Hauptmann are affiliated with the Department of Physiotherapy, Dr Beuret is affiliated with the Department of Intensive Care, and Dr Garin is affiliated with the Department of Medicine, Hospital Riviera-Chablais, Monthey, Switzerland. Dr Ratano is affiliated with the Department of Intensive Care, University Hospital of Lausanne, Lausanne, Switzerland. Dr Contal is affiliated with the University of Health Sciences (HESAV) and University of Applied Sciences and Arts Western Switzerland (HES-SO), Lausanne, Switzerland.
}

Ms Vaudan presented a version of this paper at the European Respiratory Society International Congress 2014, held September 8, 2014, in Münich, Germany. Dr Ratano presented a version of this paper at the Congress of etiologies. Two reviews of randomized controlled trials comparing the use of NIV added to standard medical therapy with standard medical therapy alone in severe COPD exacerbations showed that this technique lowers in-hospital mortality, intubation rates, and hospital stay. ${ }^{1,2}$ Other studies reported decreased ICU stay ${ }^{3-5}$ and diminished costs. ${ }^{6,7}$ A recent French multi-center cohort study based

\footnotetext{
the Swiss Society for Intensive Medicine, held October 30, 2014, in Interlaken, Switzerland.

The authors have disclosed no conflicts of interest.

Correspondence: Stéphanie Vaudan, Rue des Morasses 8, 1920 Martigny, Switzerland. E-mail: stephanie.vaudan@hopitalrivierachablais.ch.
}

DOI: $10.4187 /$ respcare. 03844 
on $15 \mathrm{y}$ of follow-up demonstrated that the use of NIV in subjects with acute-on-chronic respiratory failure improved survival. ${ }^{8}$

Nevertheless, NIV delivery is challenging with patients in respiratory distress. Issues with air leaks, patient agitation or discomfort, or lack of effective relief of the respiratory work can lead to technique failure. This necessitates quick and focused adaptations of patient position, ventilator-airway interfaces, and ventilator settings, together with continuous observation and reassurance of the patient. ${ }^{9}$ This highly time-consuming task is best achieved by specifically trained personal. Indeed, studies have reported that NIV success depends on the permanent availability of a trained staff, ${ }^{10-13}$ and the performance level of the NIV team also predicts technique efficacy.

However, there are no data on the clinical impact of the implementation of an NIV team in an acute care unit. We aimed to determine whether a dedicated NIV team would have an impact on the intubation and death risk of subjects with severe COPD exacerbations.

\section{Methods}

We conducted a retrospective study comparing 2 cohorts of subjects admitted to our ICU for COPD exacerbations. All consecutive subjects with a main discharge diagnosis of COPD were identified from the ICU admission registry and included in our study independently of the type of respiratory failure (hypercapnic vs normocapnic). The first cohort included all subjects admitted from January 1, 2001, to September 30, 2003. During this period, NIV was administered by ICU nurses and doctors, usually with ICU-designed ventilators. The second cohort included all subjects admitted from January 1, 2010, to July 1, 2012, during which time all NIV treatments were applied by the NIV team, mainly with portable ventilators dedicated to NIV.

Between the 2 study periods, an NIV team composed of 7 respiratory therapists (RTs) was assembled in our institution, a regional acute care hospital with 187 beds (including 7 multidisciplinary ICU beds), admitting $\sim 600$ patients each year. The physical therapists provided all respiratory and physical treatments, but they were specifically trained and progressively acquired skill and expertise in NIV treatments. The team first operated from 7.30 AM to 5 PM, but in October 2005, this time was extended to 11 PM. Since January 1, 2010, the team has been fully operational and providing all NIV treatments $24 \mathrm{~h} / \mathrm{d}$.

Patients were excluded if they presented an absolute contraindication for NIV: cardiac or respiratory arrest, ARDS, a pneumothorax that was not drained, uncontrollable vomiting, head and neck injuries, and hemodynamic

\section{QUICK LOOK}

\section{Current knowledge}

Noninvasive ventilation (NIV) is a standard of care for treatment of COPD exacerbations, resulting in reduced need for mechanical ventilation, morbidity, and mortality. Patient selection is as important to success as is choice of an appropriate interface and maintenance of synchrony. Time spent with the patient in the first $2 \mathrm{~h}$ by bedside caregivers has also been found to be a key to success.

\section{What this paper contributes to our knowledge}

In a single-center study, the use of an NIV team operating $24 \mathrm{~h} / \mathrm{d}$ reduced the absolute risk of death or intubation in subjects admitted to the ICU for COPD exacerbations compared with historical controls by $15 \%$. An active NIV team may improve outcomes in a facility with a large number of COPD exacerbations.

shock. We did not exclude subjects who needed only lowdose vasopressors.

The following data were collected by manual extraction from the medical file: age, sex, arterial blood gas on admission, blood pressure, heart rate, oxygen saturation, breathing frequency, Simplified Acute Physiology Score II (SAPS II), medication, type of respiratory support (invasive mechanical ventilation, NIV, and CPAP), secondary diagnosis of pneumonia or heart failure, ICU and hospital stay, and in-hospital death. Only subjects who were able to tolerate at least one session of NIV were considered to have received NIV treatment.

The primary outcome was the difference in the risk of intubation or in-hospital death between the 2 cohorts. The secondary outcomes were hospital and ICU stay.

Continuous variables are reported as mean $\pm \mathrm{SD}$ or median (interquartile range [IQR]) if not normally distributed, and categorical variables are reported as $n(\%)$. Between-group differences were assessed using the $t$ test, Wilcoxon test, chi-square test, or Fisher exact test as appropriate. We used logistic regression to test the univariate association between the baseline parameters and the primary outcome. Variables significantly associated with the outcome were then introduced in a multivariate model. Significance was defined as a 2-tailed value of $P<.05$. All analyses were done with SPSS 18.0 (SPSS, Chicago, Illinois).

This study was done according to a protocol approved by the Ethics Committee for Human Research of the Canton of Valais and complied with the principles of the Helsinki Declaration. The need for informed consent was waived. 
Table 1. Subject Characteristics at Baseline

\begin{tabular}{|c|c|c|c|}
\hline Characteristic & $\begin{array}{c}\text { January } 1,2001, \text { to September } 30 \\
2003(n=53)\end{array}$ & $\begin{array}{c}\text { January } 1,2010, \text { to July } 1, \\
2012(n=73)\end{array}$ & $P$ \\
\hline Age, mean \pm SD y & $67.2 \pm 9.0$ & $68.9 \pm 9.8$ & .32 \\
\hline Males, \% & 58.5 & 65.8 & .41 \\
\hline Temperature, mean $\pm \mathrm{SD}{ }^{\circ} \mathrm{C}$ & $36.8 \pm 0.89$ & $37.1 \pm 0.90$ & .09 \\
\hline Heart rate, mean $\pm \mathrm{SD}$ beats/min & $105 \pm 18$ & $108 \pm 22$ & .35 \\
\hline Systolic blood pressure, mean $\pm \mathrm{SD} \mathrm{mm} \mathrm{Hg}$ & $140 \pm 25$ & $134 \pm 29$ & .19 \\
\hline Diastolic blood pressure, mean $\pm \mathrm{SD} \mathrm{mm} \mathrm{Hg}$ & $79 \pm 16$ & $75 \pm 18$ & .22 \\
\hline Breathing frequency, mean $\pm \mathrm{SD}$ breaths $/ \mathrm{min}$ & $28 \pm 6$ & $29 \pm 7$ & .31 \\
\hline $\mathrm{pH}$ & $7.33 \pm 0.12$ & $7.33 \pm 0.10$ & .95 \\
\hline $\mathrm{P}_{\mathrm{aO}_{2}}$, mean $\pm \mathrm{SD}$ mm Hg & $59.5 \pm 20.4$ & $63.9 \pm 19.3$ & .22 \\
\hline $\mathrm{P}_{\mathrm{aCO}_{2}}$, mean $\pm \mathrm{SD} \mathrm{mm} \mathrm{Hg}$ & $55.9 \pm 23.4$ & $57.5 \pm 22.1$ & .68 \\
\hline Bicarbonate, mean $\pm \mathrm{SD} \mathrm{mmol} / \mathrm{L}$ & $25.4 \pm 4.1$ & $25.7 \pm 4.0$ & .68 \\
\hline Lactate, mean $\pm \mathrm{SD} \mathrm{mmol} / \mathrm{L}$ & $1.69 \pm 1.29$ & $1.59 \pm 0.86$ & .61 \\
\hline SAPS II, mean \pm SD & $30.0 \pm 5.6$ & $33.1 \pm 11.6$ & .08 \\
\hline
\end{tabular}

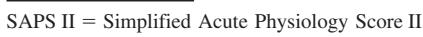

\section{Results}

Fifty-seven subjects were included in the first cohort. Four subjects were excluded, 3 because of incomplete medical record documentation and one because the main diagnosis was not a COPD exacerbation, leaving 53 subjects available for analysis. In the second cohort, 76 subjects were initially included. Three were excluded, one because of incomplete medical record documentation and 2 because the main diagnosis was not a COPD exacerbation, leaving 73 subjects available. Baseline characteristics of the 2 cohorts are provided in Table 1 . Subjects were predominantly men in their 60 s. They presented with tachycardia (combined mean heart rate for both groups $107 \pm 20$ beats/min) and tachypnea (mean breathing frequency $29 \pm 7$ breaths/min), with mild respiratory acidosis (mean pH $7.33 \pm 0.11$ ), mean $\mathrm{P}_{\mathrm{aCO}_{2}}$ of $56.8 \pm 22.6 \mathrm{~mm} \mathrm{Hg}$, and hypoxemia (mean $\mathrm{P}_{\mathrm{aO}_{2}}$ $62.1 \pm 19.8 \mathrm{~mm} \mathrm{Hg}$ ).

\section{Secondary Diagnosis and Treatment}

Secondary diagnosis and treatment are summarized in Table 2. Fewer subjects suffered from pneumonia in the first cohort $(54.7 \%$ vs $82.2 \%, P=.001)$. Antibiotics, systemic corticosteroids, and bronchodilators were prescribed for most subjects, as expected in severe COPD exacerbations. The prescription rate for the different treatments was similar in the 2 cohorts, except for NIV, which was more frequently applied in the second cohort $(64.2 \%$ vs $91.8 \%, P<.001)$.

\section{Primary and Secondary Outcomes}

Fifteen subjects (28.3\%) died or had to undergo tracheal intubation in the first cohort, and only $10(13.7 \%)$ in the
Table 2. Secondary Diagnoses and Treatments

\begin{tabular}{lccc}
\hline \hline & $\begin{array}{c}\text { January 1, 2001, } \\
\text { to September 30, } \\
2003(n=53)\end{array}$ & $\begin{array}{c}\text { January 1, 2010, } \\
\text { to }(n=73)\end{array}$ & $P$ \\
\hline Pneumonia & $29(54.7)$ & $60(82.2)$ & .001 \\
Heart failure & $14(26.4)$ & $26(35.6)$ & .27 \\
Systemic corticosteroids & $43(81.1)$ & $56(76.7)$ & .55 \\
Antibiotics & $47(88.7)$ & $69(94.5)$ & .23 \\
Inhaled bronchodilators & $48(90.6)$ & $70(95.9)$ & .23 \\
Diuretics & $20(37.7)$ & $32(43.8)$ & .49 \\
NIV* & $34(64.2)$ & $67(91.8)$ & $<.001$ \\
& & & \\
All results are given as $n$ (\%). & & & \\
$*$ Only subjects able to tolerate at least one NIV session. & & \\
NIV = noninvasive ventilation & & & \\
&
\end{tabular}

second cohort, giving a significant $(P=.04)$ absolute risk reduction of $14.6 \%$. In-hospital mortality also decreased significantly in the second cohort $(n=8[15.1 \%]$ vs $n=3$ [4.1\%], $P=.04)$. There was a trend toward decreased intubation rates in the second cohort $(n=11$ [20.8\%] vs $n=8$ [11.0\%], $P=.13$ ). Median ICU and hospital stay decreased in the second cohort from $3.1 \mathrm{~d}$ (IQR 1.5-8.7) to $1.9 \mathrm{~d}$ (IQR 1.2-3.5) $(P=.04)$ and from $11.5 \mathrm{~d}$ (IQR 8.5-20.2) to $9.6 \mathrm{~d}$ (IQR 6.3-13.4) $(P=.04)$, respectively.

\section{Risk Factors for Intubation or Death By Uni- and Multivariate Analyses}

Univariate associations between subject characteristics and risk of intubation or death are presented in Table 3 . $\mathrm{P}_{\mathrm{aCO}}, \mathrm{pH}$, SAPS II, temperature, $\mathrm{P}_{\mathrm{aO}_{2}}$, and NIV use were all significantly associated with outcomes. The relative 


\section{Dedicated NIV Team for Severe COPD Exacerbations}

Table 3. Risk of Death or Intubation (Univariate)

\begin{tabular}{|c|c|c|c|c|c|}
\hline Parameter & $\begin{array}{l}\text { Death or Intubation } \\
\quad(n=25)\end{array}$ & $\begin{array}{l}\text { Survived Without Intubation } \\
\qquad(n=101)\end{array}$ & Odds Ratio & $95 \% \mathrm{CI}$ & $P$ \\
\hline Age, mean \pm SD y & $69.8 \pm 8.1$ & $67.7 \pm 9.8$ & 1.02 & $0.98-1.07$ & .32 \\
\hline Males, $n(\%)$ & $15(60.0)$ & $64(63.4)$ & 1.15 & $0.47-2.82$ & .76 \\
\hline Temperature, mean $\pm \mathrm{SD}{ }^{\circ} \mathrm{C}$ & $36.6 \pm 0.9$ & $37.1 \pm 0.9$ & 0.47 & $0.25-0.87$ & .02 \\
\hline Heart rate, mean $\pm \mathrm{SD}$ beats $/ \mathrm{min}$ & $114 \pm 22$ & $105 \pm 20$ & 1.02 & $1.00-1.05$ & .050 \\
\hline Systolic blood pressure, mean $\pm \mathrm{SD} \mathrm{mm} \mathrm{Hg}$ & $137 \pm 28$ & $136 \pm 27$ & 1.00 & $0.99-1.02$ & .95 \\
\hline Diastolic blood pressure, mean $\pm \mathrm{SD} \mathrm{mm} \mathrm{Hg}$ & $75 \pm 16$ & $77 \pm 18$ & 0.99 & $0.97-1.02$ & .58 \\
\hline Breathing frequency, mean \pm SD breaths/min & $31 \pm 7$ & $28 \pm 6$ & 1.06 & $0.99-1.13$ & .09 \\
\hline $\mathrm{pH}$, mean $\pm \mathrm{SD}$ & $7.23 \pm 0.17$ & $7.36 \pm 0.07$ & 0.89 & $0.85-0.94$ & $<.001$ \\
\hline $\mathrm{P}_{\mathrm{aO}_{2}}$, mean $\pm \mathrm{SD} \mathrm{mm} \mathrm{Hg}$ & $70.6 \pm 20.5$ & $60.0 \pm 19.2$ & 1.03 & $1.00-1.05$ & .02 \\
\hline $\mathrm{P}_{\mathrm{aCO}_{2}}$, mean $\pm \mathrm{SD} \mathrm{mm} \mathrm{Hg}$ & $77.4 \pm 36.5$ & $51.7 \pm 13.7$ & 1.05 & $1.03-1.07$ & $<.001$ \\
\hline Bicarbonate, mean $\pm \mathrm{SD}$ mmol/L & $24.2 \pm 4.1$ & $25.9 \pm 4.0$ & 0.90 & $0.80-1.00$ & .060 \\
\hline Lactate, mean $\pm \mathrm{SD} \mathrm{mmol} / \mathrm{L}$ & $1.6 \pm 1.1$ & $1.6 \pm 1.1$ & 1.01 & $0.67-1.53$ & .95 \\
\hline SAPS II, mean \pm SD & $37 \pm 10$ & $30 \pm 9$ & 1.07 & $1.02-1.12$ & .004 \\
\hline Corticosteroid treatment, $n(\%)$ & $16(64)$ & $83(82)$ & 0.39 & $0.15-1.01$ & .047 \\
\hline Antibiotic treatment, $n(\%)$ & $23(92.0)$ & $93(92.1)$ & 0.99 & $0.20-4.98$ & .99 \\
\hline Diuretic treatment, $n(\%)$ & $10(40.0)$ & $42(41.6)$ & 0.94 & $0.38-2.29$ & .89 \\
\hline NIV treatment, $n(\%)$ & $16(64.0)$ & $98(97.0)$ & 0.25 & $0.13-0.48$ & $<.001$ \\
\hline Second diagnosis of pneumonia, $n(\%)$ & $17(68.0)$ & $72(71.3)$ & 0.86 & $0.33-2.20$ & .75 \\
\hline Second diagnosis of heart failure, $n(\%)$ & $8(32.0)$ & $32(31.7)$ & 1.02 & $0.40-2.60$ & .98 \\
\hline Second cohort, $n(\%)$ & $10(40.0)$ & $63(62.4)$ & 0.40 & $0.16-0.99$ & .046 \\
\hline
\end{tabular}

Table 4. Risk of Death or Intubation (Multivariate)

\begin{tabular}{lcc}
\hline \hline & Adjusted Odds Ratio & $95 \% \mathrm{CI}$ \\
\hline Cohort 2 vs 1 & 0.20 & $0.06-0.70$ \\
SAPS II & 1.09 & $1.01-1.18$ \\
$\mathrm{P}_{\mathrm{aCO}}$ & 1.04 & $1.01-1.07$ \\
$\mathrm{P}_{\mathrm{aO}}$ & 1.01 & $0.98-1.04$ \\
Temperature & 0.70 & $0.35-1.41$
\end{tabular}

SAPS II $=$ Simplified Acute Physiology Score II

risk of death or intubation was 0.40 in the second cohort versus the first cohort (95\% CI 0.16-0.99, $P=.046$ ).

As we expected strong collinearity between $\mathrm{P}_{\mathrm{aCO}}$ and $\mathrm{pH}$, we introduced only the first variable in the multivariate analysis. Although significant, NIV use was not introduced because it was on the causality pathway between the predictive variable (ie, the 2 different cohorts) and the main outcomes. Subjects in the second cohort had an adjusted odds ratio of 0.20 (95\% CI 0.06-0.70) for death or intubation $(P=.01)$ (Table 4$)$.

\section{Discussion}

We found a $14.6 \%$ reduction in the absolute risk of death or intubation in subjects admitted to the ICU for severe COPD exacerbations in 2010-2012 compared with 2001-2003 (60\% reduction in the relative risk). This occurred despite a trend toward higher SAPS II in the 20102012 cohort (mean SAPS II 33.1 vs 30.0, $P=.08$ ), suggesting that the exacerbation severity was higher in subjects admitted in the second cohort. The risk was further reduced after adjustment for variables associated with the outcome of the logistic regression. The secondary outcomes also pointed toward better results in the second cohort, with lower risk of death and intubation and shorter ICU and hospital stay.

Applied treatments did not differ significantly between the 2 cohorts, with the exception of NIV. In the second cohort, $91.8 \%$ of subjects received at least one trial of NIV compared with $64.2 \%$ in the first cohort $(P<.001)$. The difference between the 2 cohorts in the proportion of subjects receiving at least one trial of NIV may be related to better tolerance of the treatment due to more expertise of the RTs delivering the intervention.

Hence, the better prognosis of subjects in the second cohort is probably related to extended and more efficient use of NIV due to its administration by a staff highly skilled in this technique. ${ }^{14}$ It has been repeatedly demonstrated that the availability of RTs skilled and widely experienced in NIV is mandatory for its full success. The multiple devices dedicated to NIV delivery with increasing numbers of ventilation and monitoring parameters and 


\section{Dedicated NIV Team for Severe COPD Exacerbations}

available interfaces allow better adaptation of the ventilation to the specific needs of a patient. ${ }^{6}$

However, this also mandates extended knowledge of a vast array of devices, a challenge that is better met if all treatments are administered by a limited number of professionals, ensuring sufficient training in the technique. An RT dedicated to NIV is likely to have more time to devote to ventilation and fine-tuning of the ventilator parameters than if NIV is administered by an ICU nurse or physician.

This difference can be explained by better tolerance of NIV due to greater expertise and by the availability at any time of a qualified RT who has time and confidence in the efficacy of NIV as an initial treatment. The use of a dedicated ventilator with a single-limb circuit with a leak port and adaptable interface may increase the tolerance, comfort, and efficacy of NIV.9,15 Many patients with advanced COPD do not wish to undergo tracheal intubation in case of respiratory failure refractory to noninvasive management. However, NIV has been also proven to benefit to elderly patients with hypercapnic respiratory failure and do-not-intubate orders by lowering the mortality risk. ${ }^{16}$ To maximize the external validity of our study, we chose to include all subjects admitted to the ICU irrespective of the presence of any do-not-intubate or do-not-resuscitate orders. To take into account the fact that NIV failure would not result in intubation for such patients, we defined the primary outcome as the composite of intubation or in-hospital death. A similar measure of the global benefit of NIV in COPD exacerbations has been used in a Cochrane review. ${ }^{5}$

We decided not to report the $\mathrm{F}_{\mathrm{IO}_{2}}$, as this measure was not precise (most subjects received supplemental oxygen via nasal cannula or air-entrainment masks when arterial blood gases were analyzed). Although $\mathrm{P}_{\mathrm{aO}_{2}}$ did not differ significantly between the 2 cohorts, it was not adjusted for the $\mathrm{F}_{\mathrm{IO}_{2}}$ received, as there is no means to evaluate it reliably under these conditions.

Pneumonia was significantly more frequent in the second cohort $(54.7 \%$ vs $82.2 \%, P=.001)$. This difference is in line with greater severity of illness in the second cohort. However, a confounding factor was present, as there was a change in the reimbursement method for hospital stays between the 2 considered periods, with the introduction of diagnosis-related groups. This change might have induced an increase in the documentation of a secondary diagnosis in the second cohort.

Our study has several strengths. It was conducted on consecutive subjects, used strict inclusion criteria, and searched thoroughly for systematic differences between subjects admitted during the 2 time periods. Its main weakness is that it was a retrospective chart review. We could not measure which part of the observed improvement was related to an institutional trend, with improvement of technical issues and better dissemination of NIV standards of care, and which part was specifically due to the implementation of a team dedicated to NIV delivery.

\section{Conclusions}

The implementation of a dedicated NIV team of trained RTs available $24 \mathrm{~h} / \mathrm{d}$ was associated with a significant decrease in the risk of death or intubation for severe COPD exacerbations. Any hospital admitting subjects with respiratory failure secondary to COPD exacerbations should consider such a team.

\section{REFERENCES}

1. Boldrini R, Fasano L, Nava S. Noninvasive mechanical ventilation. Curr Opin Crit Care 2012;18(1):48-53.

2. Keenan SP, Sinuff T, Burns KE, Muscedere J, Kutsogiannis J, Mehta S, et al. Clinical practice guidelines for the use of noninvasive positivepressure ventilation and noninvasive continuous positive airway pressure in the acute care setting. CMAJ 2011;183(3):E195-E214.

3. Peter JV, Moran JL, Phillips-Hughes J, Warn D. Noninvasive ventilation in acute respiratory failure-a meta-analysis update. Crit Care Med 2002;30(3):555-562.

4. Keenan SP, Sinuff T, Cook DJ, Hill NS. Which patients with acute exacerbation of chronic obstructive pulmonary disease benefit from noninvasive positive-pressure ventilation? A systematic review of the literature. Ann Intern Med 2003;138(11):861-870.

5. Lightowler JV, Wedzicha JA, Elliott MW, Ram FS. Non-invasive positive pressure ventilation to treat respiratory failure resulting from exacerbations of chronic obstructive pulmonary disease: Cochrane systematic review and meta-analysis. BMJ 2003;326(7382):185.

6. Plant PK, Owen JL, Parrott S, Elliott MW. Cost effectiveness of ward based non-invasive ventilation for acute exacerbations of chronic obstructive pulmonary disease: economic analysis of randomised controlled trial. BMJ 2003;326(7396):956.

7. Keenan SP, Gregor J, Sibbald WJ, Cook D, Gafni A. Noninvasive positive pressure ventilation in the setting of severe, acute exacerbations of chronic obstructive pulmonary disease: more effective and less expensive. Crit Care Med 2000;28(6):2094-2102.

8. Schnell D, Timsit JF, Darmon M, Vesin A, Goldgran-Toledano D, Dumenil AS, et al. Noninvasive mechanical ventilation in acute respiratory failure: trends in use and outcomes. Intensive Care Med 2014;40(4):582-591.

9. Hess DR. Noninvasive ventilation for acute respiratory failure. Respir Care 2013;58(6):950-972.

10. Elliott MW, Confalonieri M, Nava S. Where to perform noninvasive ventilation? Eur Respir J 2002;19(6):1159-1166.

11. Wood KA, Lewis L, Von Harz B, Kollef MH. The use of noninvasive positive pressure ventilation in the emergency department: results of a randomized clinical trial. Chest 1998;113(5):1339-1346.

12. Girou E, Brun-Buisson C, Taillé S, Lemaire F, Brochard L. Secular trends in nosocomial infections and mortality associated with noninvasive ventilation in patients with exacerbation of COPD and pulmonary edema. JAMA 2003;290(22):2985-2991.

13. Nava S, Ceriana P. Causes of failure of noninvasive mechanical ventilation. Respir Care 2004;49(3):295-303.

14. Nava S, Hill N. Non-invasive ventilation in acute respiratory failure. Lancet 2009;374(9685):250-259.

15. Hess DR, Branson RD. Know your ventilator to beat the leak. Chest 2012;142(2):274-275.

16. Nava S, Grassi M, Fanfulla F, Domenighetti G, Carlucci A, Perren A, et al. Non-invasive ventilation in elderly patients with acute hypercapnic respiratory failure: a randomised controlled trial. Age Ageing 2011;40(4):444-450. 